\title{
Pharmacokinetics of a 1,000 mg Disintegrating Aspirin Tablet Formulation
}

\section{Forder $S^{1}$ and Voelker $\mathbf{M}^{\star 2}$}

${ }^{1}$ Global Medical Affairs Consumer Health, Bayer Corporation, Whippany, NJ, USA

${ }^{2}$ Global Medical Affairs Consumer Health, Bayer AG, Leverkusen, Germany

${ }^{*}$ Corresponding author: Voelker M, Bayer Consumer Health Global Medical, 51366 Leverkusen, Germany, E-mail: michael.voelker@bayer.com

Citation: Forder S, Voelker M (2018) Pharmacokinetics of a 1,000 mg Disintegrating Aspirin Tablet Formulation. J Pharma Drug Develop 5(1): 101

Received Date: July 4, 2018 Accepted Date: November 19, 2018 Published Date: November 21, 2018

\begin{abstract}
Migraine is a global disorder and considerably affecting people`s quality of life. Treatments include nonsteroidal anti-inflammatory drugs-containing medicinal products among whom acetylsalicylic acid-containing Aspirin ${ }^{\circledR}$ has been proven effectively to relief migraine headache. Early treatment is recommended for patients with migraine attacks.

A requirement for early onset of action includes tablet disintegration and consequent active ingredient dissolution and absorption. The bioavailability of a new quickly disintegrating $1,000 \mathrm{mg}$ aspirin formulation has been investigated in a bioequivalence study versus a marketed Aspirin ${ }^{\oplus}$ formulation with clinically demonstrated early onset of action. The new formulation has a tablet strength (1,000 $\mathrm{mg}$ ) and time to maximum plasma concentration (mean 21.6 minutes) providing upside for people requiring treatment of migraine headache.
\end{abstract}

Keywords: Aspirin; acetylsalicylic acid; salicylic acid; pharmacokinetic; bioavailability; bioequivalence; disintegration; migraine

\section{Introduction}

The burden of migraine is considerable, as it affects $11 \%$ of people globally and significantly diminishes the quality of life and normal functioning of most sufferers [1]. The role of non-prescription medicinal product treatment options for acute migraine episodes is large, as a majority of patients opt for self-treatment over medical consultation with a physician [2]. Aspirin (acetylsalicylic acid, ASA) in doses of 1,000 $\mathrm{mg}$ has been proven to effectively relief migraine headache [3-13].

A rapid onset of action is desirable for relief of acute pain in general, but holds even more weight in the case of migraine headache. In this context, timing of relief may have clinical relevance. Research has suggested a link between adequate treatment early in the course of migraine attack, while headache pain is still mild, and better outcomes [14-18].

Bayer previously developed a $500 \mathrm{mg}$ quickly disintegrating aspirin coated tablet with microactive technology, which was proven to enhance bioavailability [19] and improve onset of action compared to regular aspirin tablets [20,21]. This enhanced speed can be attributed to two formulation enhancements: micronized aspirin particles that are smaller in size, providing a larger surface area for dissolution and absorption, and sodium carbonate which acts as a disintegrant and local buffer both resulting in improved pharmacokinetics $[19,20,22]$.

Using the microactive technology, a new 1,000 mg quickly disintegrating aspirin coated tablet has been developed with the aim of providing quick disintegration, dissolution, bioavailability and consequent fast onset of action in patients with migraine. The new formulation is doubling the amount of drug substance, excipients and dry coating. This study sought to evaluate the pharmacokinetic profile of the 1 x 1,000 mg aspirin tablet compared to the currently marketed 2 x 500 mg Aspirin ${ }^{\oplus}$ tablet, and evaluate for bioequivalence of the two formulations.

\section{Methods}

\section{Study Design and Procedures}

The study was a phase I, single-center, randomized, open-label, single-dose, two-treatment, two-period crossover, pharmacokinetic study in healthy male and female adults. To qualify for enrollment, participants were required to provide written informed consent and be healthy, non-smoking, 18 to 55 year old and a body mass index of 18 to $30 \mathrm{~kg} / \mathrm{m}^{2}$. The study consisted of a 14 -day screening phase, a treatment phase with dosing period 1 and dosing period 2, and a 4-day follow-up. Final protocol and informed consent 
forms were approved by the appropriate Ethical Review Board. The study was conducted under Good Clinical Practice and the ethical principles of the Declaration of Helsinki.

The study was conducted between February 17 and March 13, 2014 by Frontage Clinical Services, Hackensack, New Jersey, United States. Eligible subjects were admitted to the site on the evening prior to dosing (Day 0), to be evaluated for continued eligibility and undergo an overnight fast. At approximately 8 am the following morning, (Day 1) subjects were administered their assigned treatment. Each received a single dose of 1,000 mg acetylsalicylic acid, either as a $1 \mathrm{x} 1000 \mathrm{mg}$ aspirin tablet (test treatment) or 2 x $500 \mathrm{mg}$ Aspirin ${ }^{\circledast}$ tablets (reference treatment). Subjects maintained their fast until 4-hours post-dose, but water was permitted up to 1 hour pre-dose and after 2-hours post-dose. Subjects remained in-house for 24-hours of blood sampling. Blood draws were collected prior to dosing (baseline) and at $5,7.5,10,12.5,15,17.5,20,22.5,25,27.5,30,35,40,45,50,55$ minutes and at $1,1.25$, $1.5,2,3,4,5,6,8,12,24$ hours post-dose.

A washout period of at least 7 days was required (from time of first dose) before subjects returned to the site for dosing period 2 . At the conclusion of dosing period 2, subjects underwent their end-of-trial procedures and review of adverse events before being discharged from the trial. A follow-up phone call was placed to each participant within 4-days of discharge evaluating for adverse events and concomitant medications.

The primary pharmacokinetic parameters evaluated were area under the plasma concentration-time curve from time zero to the time of last measurable concentration $\left(\mathrm{AUC}_{0-\mathrm{t}}\right)$, $\mathrm{AUC}$ from time zero extrapolated to infinity $\left(\mathrm{AUC}_{0 \text {-inf }}\right)$, and maximum plasma concentration (Cmax) for ASA. As secondary outcomes, the $\mathrm{AUC}_{0-\mathrm{t}}, \mathrm{AUC}_{0 \text {-inf }}$ and $\mathrm{C}_{\max }$ for the active metabolite salicylic acid (SA) were determined, as well as time to reach maximum plasma concentration $\left(\mathrm{t}_{\max }\right)$, half-life $\left(\mathrm{t}_{1 / 2}\right)$, and apparent terminal rate constant $\left(\lambda_{z}\right)$ for both analytes. Safety of the products was evaluated by subject's self-reported adverse events and consequent assessment by the investigators and by clinical parameters (systolic/diastolic blood pressure, respiratory rate, pulse rate, physical examination, clinical and laboratory testing). Adverse events reports were collected throughout the trial, from screening through follow-up.

\section{Statistical Methods}

Under the assumption of $\mu$ Test $/ \mu$ Reference $=1.0, \mathrm{CV}=25.0 \%$, acceptance range for equivalence: $0.8-1.25$ it was determined that 30 subjects (15 per sequence group) would be adequate for the study to achieve $80 \%$ power and a significance level of $5 \%$. To account for potential dropouts (which were not to be replaced unless the population dropped lower than 30), the study planned to enroll 38 subjects.

Pharmacokinetic analyses were performed on the pharmacokinetic (PK) Evaluable Population (all subjects having $\mathrm{C}_{\max }$ and $\mathrm{AUC}_{0-\mathrm{t}}$ data for both treatments and no major protocol deviations). Supportive analyses were run using the PK Full Population (all subjects that were randomized and had plasma concentration data). Safety evaluations were based on the Safety Population (all subjects who received at least 1 dose of study drug). Plasma concentration-time data for both ASA and SA were summarized at each measured time point using descriptive statistics. PK parameters were calculated from the plasma concentration data using actual sample times and standard, non-compartmental methods of analysis (WinNonlin Professional version 6.3.1) and analyzed using analysis of variance (ANOVA).

The evaluation of bioequivalence for test versus reference products was based upon ASA data for $\mathrm{C}_{\max }, \mathrm{AUC}_{0 \mathrm{t}}$, and $_{\mathrm{AUC}} \mathrm{AU}_{0 \text {-inf }} \mathrm{A} 90 \%$ confidence interval (CI) for the difference between formulations was obtained. If the $90 \%$ CIs of the ratios for $\mathrm{Cmax}_{\mathrm{aUC}} \mathrm{AUC}_{0 \mathrm{t}}$, and $\mathrm{AUC}_{0 \text {-inf }}$ for test vs. reference treatment in the PK Evaluable Population were contained within 80-125\%, then the formulations would be considered bioequivalent. As supportive analyses, the same test of bioequivalence was performed for SA in the PK Evaluable Population.

\section{Results}

\section{Study Population}

Thirty-eight subjects were randomized to receive treatment, of which 36 (94.7\%) completed the trial and were included in the PK Evaluable Population. Two subjects discontinued prematurely (due to inadequate venous access and withdrawal of informed consent) and were only included in the PK Full and Safety Populations. Twenty-three (60.5\%) subjects were male and 15 (39.5\%) subjects were female, with ages ranging from 18 to 55 (mean $(\mathrm{SD})=37(10.7)$ ). A more complete list of study population demographics and baseline characteristics can be found in Table 1.

\section{PK Parameters \& Bioequivalence}

Summary statistics for ASA and SA pharmacokinetic parameters are presented in Table 2. Plasma concentration vs. time curves for ASA and SA analytes are shown in Figures 1 and 2. The curves obtained for the 1 x 1,000 mg aspirin tablet (test) are consistent with those obtained for the $2 \times 500 \mathrm{mg}$ Aspirin ${ }^{\oplus}$ tablets (reference). This indicates that the formulations behaved similarly in terms of the speed of the ASA absorption (median $\mathrm{t}_{\text {max }}$ (range): $0.38 \mathrm{~h}(0.25,0.58)$ and $0.33 \mathrm{~h}(0.21,0.67)$ ) for test and reference, respectively). Mean peak plasma ASA level were also similar (geometric mean $\mathrm{C}_{\max }(\mathrm{SD}): 22.46 \mu \mathrm{g} / \mathrm{mL}(1.295)$ and $20.18 \mu \mathrm{g} / \mathrm{mL}$ (1.406) for test 


\begin{tabular}{|l|c|c|}
\hline Demographics & Statistics & Overall (N = 38) \\
\hline & Mean (SD) & $37.0(10.7)$ \\
Age (years) & Median & 39.0 \\
& Range & $18-55$ \\
\hline Gender & & \\
Male & $\mathrm{n}(\%)$ & $23(60.5)$ \\
Female & $\mathrm{n}(\%)$ & $15(39.5)$ \\
\hline Race & & \\
White & $\mathrm{n}(\%)$ & $24(63.2)$ \\
Black & $\mathrm{n}(\%)$ & $13(34.2)$ \\
Other & $\mathrm{n}(\%)$ & $1(2.6)$ \\
\hline & Mean $(\mathrm{SD})$ & $75.42(13.23)$ \\
Weight $(\mathrm{kg})$ & Median & 75.82 \\
& Range & $52-99$ \\
\hline & Mean (SD) & $168.68(10.28)$ \\
Height $(\mathrm{cm})$ & Median & 167.89 \\
& Range & $151-193$ \\
\hline & Mean (SD) & $26.54(2.58)$ \\
BMI $\left(\mathrm{kg} / \mathrm{m}^{2}\right)$ & Median & 27.05 \\
& Range & $21-30$ \\
\hline
\end{tabular}

Table 1: Demographics and Baseline Characteristics (Safety Population)

\begin{tabular}{|c|c|c|c|c|c|}
\hline \multirow{2}{*}{$\begin{array}{l}\text { PK Parameter } \\
\text { (Unit) }\end{array}$} & \multirow[b]{2}{*}{ Statistics } & \multicolumn{2}{|c|}{ Acetylsalicylic Acid } & \multicolumn{2}{|c|}{ Salicylic Acid } \\
\hline & & $\begin{array}{c}\text { Test } \\
(1,000 \mathrm{mg})\end{array}$ & $\begin{array}{c}\text { Reference } \\
(2 \times 500 \mathrm{mg})\end{array}$ & $\begin{array}{c}\text { Test } \\
(1,000 \mathrm{mg})\end{array}$ & $\begin{array}{c}\text { Reference } \\
(2 \times 500 \mathrm{mg})\end{array}$ \\
\hline $\mathrm{AUC}_{0-\mathrm{t}}(\mu \mathrm{g} \times \mathrm{h} / \mathrm{mL})$ & $\begin{array}{c}\text { Geometric mean (SD) } \\
\text { Median } \\
\text { Min, Max }\end{array}$ & $\begin{array}{c}11.44(1.235) \\
11.23 \\
7.64,18.58\end{array}$ & $\begin{array}{c}11.19(1.267) \\
10.61 \\
7.53,18.31\end{array}$ & $\begin{array}{c}514.4(1.368) \\
533.6 \\
277.5,1151\end{array}$ & $\begin{array}{c}507.3(1.342) \\
505.5 \\
283.9,1010\end{array}$ \\
\hline $\mathrm{AUC}_{0 \text {-inf }}(\mu \mathrm{g} \times \mathrm{h} / \mathrm{mL})$ & $\begin{array}{c}\text { Geometric mean (SD) } \\
\text { Median } \\
\text { Min, Max }\end{array}$ & $\begin{array}{c}11.46(1.235) \\
11.26 \\
7.67,18.60\end{array}$ & $\begin{array}{c}11.22(1.266) \\
10.64 \\
7.56,18.36\end{array}$ & $\begin{array}{c}522.8(1.392) \\
541.3 \\
277.5,1253\end{array}$ & $\begin{array}{c}513.5(1359) \\
511.9 \\
284.0 .1064\end{array}$ \\
\hline $\mathrm{C}_{\max }(\mu \mathrm{g} / \mathrm{mL})$ & $\begin{array}{c}\text { Geometric mean (SD) } \\
\text { Median } \\
\text { Min, Max }\end{array}$ & $\begin{array}{c}22.46(1.295) \\
23.35 \\
11.20,40.60\end{array}$ & $\begin{array}{c}20.18(1.406) \\
21.15 \\
6.85,37.10\end{array}$ & $\begin{array}{c}74.39(1.197) \\
72.15 \\
49.20,106.0\end{array}$ & $\begin{array}{c}73.09(1.206) \\
71.35 \\
49.10,108.0\end{array}$ \\
\hline $\mathrm{t}_{\max }(\mathrm{h})$ & $\begin{array}{l}\text { Mean (SD) } \\
\text { Median } \\
\text { Min, Max }\end{array}$ & $\begin{array}{c}0.36(0.09) \\
0.38 \\
0.25,0.58\end{array}$ & $\begin{array}{c}0.36(0.11) \\
0.33 \\
0.21,0.67\end{array}$ & $\begin{array}{c}0.84(0.35) \\
0.72 \\
0.38,2.00\end{array}$ & $\begin{array}{c}0.93(0.67) \\
0.80 \\
0.29,4.00\end{array}$ \\
\hline$t_{1 / 2}(h)$ & $\begin{array}{l}\text { Mean (SD) } \\
\text { Median } \\
\text { Min, Max }\end{array}$ & $\begin{array}{c}0.46(0.09) \\
0.44 \\
0.32,0.67\end{array}$ & $\begin{array}{c}0.46(0.08) \\
0.45 \\
0.35,0.64\end{array}$ & $\begin{array}{c}3.12(1.42) \\
2.63 \\
1.80 .8 .99\end{array}$ & $\begin{array}{c}2.99(1.77) \\
2.62 \\
1.75,7.55\end{array}$ \\
\hline$\lambda_{z}(/ h)$ & $\begin{array}{c}\text { Geometric mean }(\mathrm{SD}) \\
\text { Median } \\
\text { Min, Max }\end{array}$ & $\begin{array}{c}1.532(1.213) \\
1.583 \\
1.035,2179\end{array}$ & $\begin{array}{c}1.547(1.196) \\
1.556 \\
1.075,1.992\end{array}$ & $\begin{array}{c}0.238(1.419) \\
0.263 \\
0.077,0.386\end{array}$ & $\begin{array}{c}0.245(1.372) \\
0.265 \\
0.092,0.396\end{array}$ \\
\hline
\end{tabular}

Table 2: Summary Statistics of ASA and SA PK Parameters (PK Evaluable Population)

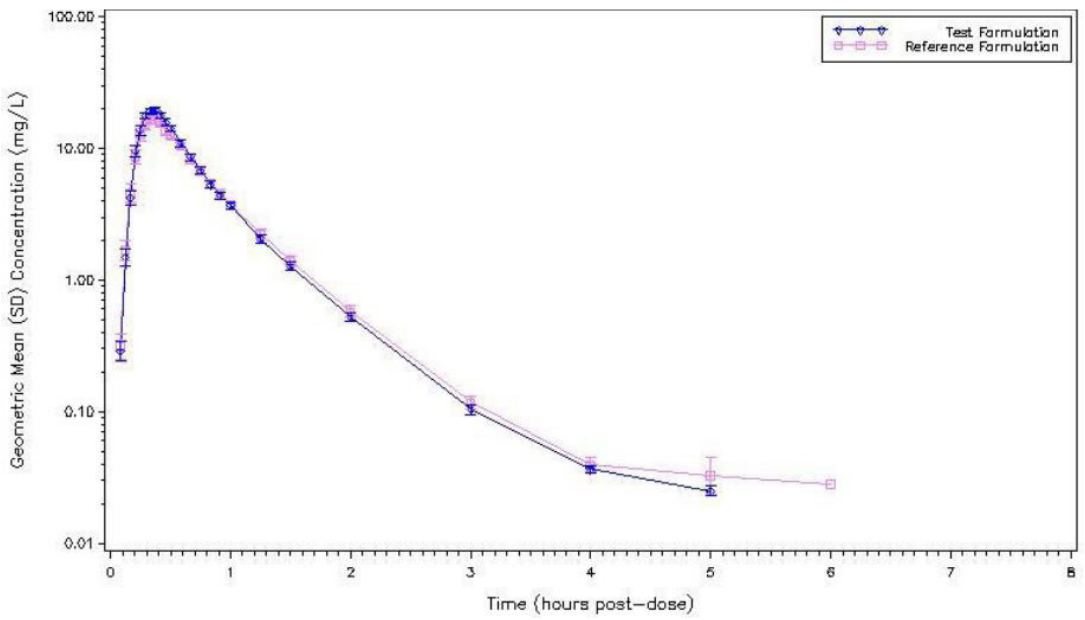

Figure 1: Geometric mean ASA plasma concentrations versus time by treatment (test formulation $=1,000 \mathrm{mg}$ aspirin, reference formulation $=2 \times 500 \mathrm{mg}$ Aspirin $^{\circledR}$ ) 


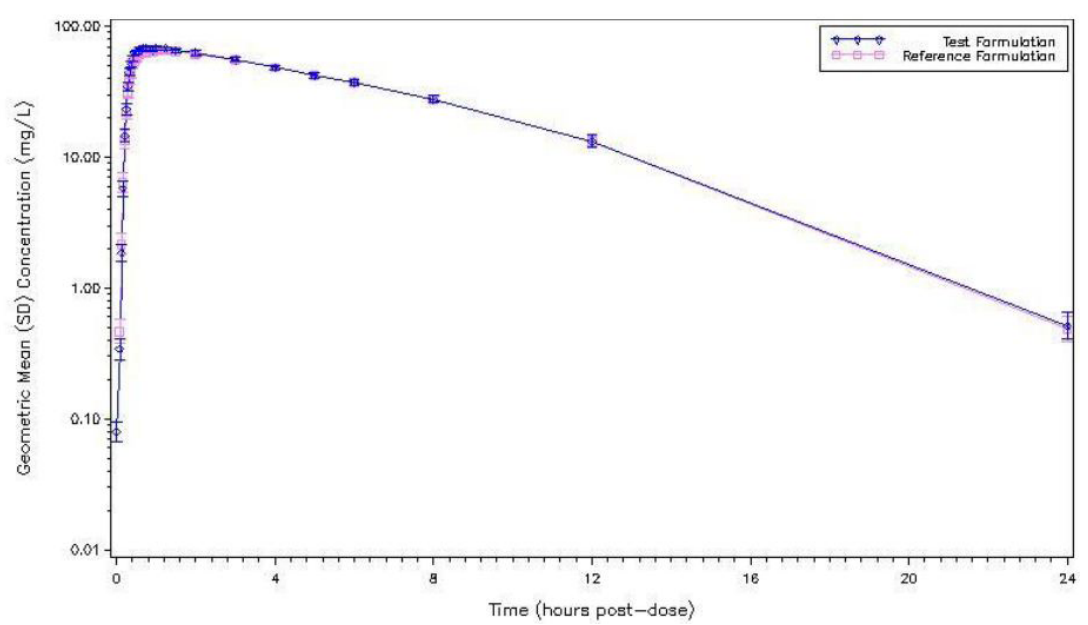

Figure 2: Geometric mean SA plasma concentrations versus time by treatment (test formulation $=1,000 \mathrm{mg}$ aspirin, reference formulation $=2 \times 500 \mathrm{mg}$ Aspirin $^{\circledR}$ )

\begin{tabular}{|c|c|c|}
\hline \multirow[t]{2}{*}{ PK Parameter (Unit) } & \multicolumn{2}{|c|}{$\begin{array}{c}\text { Ratio of geometric means (\%) } 90 \% \text { CI } \\
\left.\text { Test/Reference (1,000 mg aspirin / } 2 \text { x } 500 \text { mg Aspirin }{ }^{\circledR}\right)\end{array}$} \\
\hline & ASA & SA \\
\hline $\operatorname{Cmax}(\mu \mathrm{g} / \mathrm{mL})$ & $\begin{array}{c}110.6 \\
102.1-119.8\end{array}$ & $\begin{array}{c}101.6 \\
99.13-104.2\end{array}$ \\
\hline AUC0-t ( $\mu \mathrm{g} \times \mathrm{h} / \mathrm{mL})$ & $\begin{array}{c}102.0 \\
98.29-105.8\end{array}$ & $\begin{array}{c}101.5 \\
99.76-103.3\end{array}$ \\
\hline AUC0-inf $(\mu g \times h / m L)$ & $\begin{array}{c}102.0 \\
98.28-105.8\end{array}$ & $\begin{array}{c}101.8 \\
99.90-103.7\end{array}$ \\
\hline
\end{tabular}

Table 3: Summary of Bioequivalence Analysis of ASA and SA Plasma Analysis (PK Evaluable Population)

and reference, respectively). Speed of SA absorption (median $\mathrm{t}_{\max }$ (range): $0.72 \mathrm{~h}(0.38,2.00)$ and $0.80 \mathrm{~h}(0.29,4.00)$ for test and reference, respectively) and SA mean peak plasma SA levels (geometric mean $\mathrm{C}_{\max }$ (SD): $74.39 \mu \mathrm{g} / \mathrm{mL}(1.197) \mathrm{and} 73.09 \mu \mathrm{g} / \mathrm{mL}$ (1.206) for test and reference, respectively) further supports equivalence of the two formulations. Total exposure of drug measured as $\mathrm{AUC}_{0-\mathrm{t}}$ and $\mathrm{AUC}_{0 \text {-inf }}$ showed similar bioavailability of the two formulation regarding acetylsalicylic acid as well as salicylic acid. Results were consistent between formulations, with no sizable differences to note. This was confirmed by bioequivalence analysis presented in Table 3. The 90\% CIs for the ratio of geometric means comparing test to reference formulation fell within the accepted range of 80 to $125 \%$ for each of the three primary PK parameters $\mathrm{C}_{\max }$ (102.1-119.8), $\mathrm{AUC}_{0-\mathrm{t}}(98.29-105.8)$, and $\mathrm{AUC}_{0 \text {-inf }}$ (98.28105.8), confirming that 1 tablet of the $1,000 \mathrm{mg}$ quickly disintegrating aspirin formulation is bioequivalent to 2 tablets of $500 \mathrm{mg}$ quickly disintegrating Aspirin ${ }^{\circledast}$ formulation. A supportive analysis applying calculation of bioequivalence to the active metabolite $\mathrm{SA}$ also met criteria for bioequivalence $\left(\mathrm{C}_{\max }: 99.13-104.2, \mathrm{AUC}_{0-\mathrm{t}}: 99.76-103.3, \mathrm{AUC}_{0 \text {-inf }}: 99.90-103.7\right)$.

\section{Safety}

Adverse events occurred in 3 subjects following test drug (7.9\%) and 1 subject (2.8\%) following reference drug administration, but overall the occurrence of events was low. The adverse events reported in the test group were considered to be drug related by the Investigator. One subject reported upper abdominal pain and 2 subjects increased alanine aminotransferase. None of the subjects discontinued treatment due to an adverse event. All events were considered mild to moderate in intensity, with no reports of serious adverse events during this trial. The one adverse event reported in the reference group was considered as not related (viral infection).

\section{Discussion}

This study was conducted to compare the bioavailability of a single 1,000 mg quickly disintegrating acetylsalicylic acid tablet to two tablets of commercially available $500 \mathrm{mg}$ quickly disintegrating Aspirin ${ }^{\circledR}$. Both formulations apply small particle size active ingredients and sodium carbonate acting as a disintegrant. This microactive technology supports the pharmaceutical phase, i.e. quick disintegration and dissolution and consequent fast bioavailibilty resulting in early onset of action. This was demonstrated in in vitro dissolution and in vivo Phase I and Phase III studies for the $500 \mathrm{mg}$ formulation [19-21]. The study presented demonstrated that both microactive technology formulations are bioequivalent and have similar small time to maximum plasma concentration. Therefore, the substantial improvement in speed of dissolution, absorption, and subsequent onset of action already demonstrated for the $500 \mathrm{mg}$ quickly disintegrating tablet formulation, can also be assumed of this new higher dose formulation.

In relation to speed, there are less obvious but important formulation driven benefits resulting from the microactive technology worthy of discussion. The first is the pharmaceutical behavior of quickly disintegrating aspirin tablets in the stomach. Acetylsalicylic 
acid from standard aspirin tablets is primarily absorbed in the small intestine [23], putting speed of absorption at the mercy of gastric emptying rate. In quickly disintegrating aspirin formulations, however, microactive technology, consisting of small active ingredient particles with a relatively large surface enabling easy dissolution and sodium carbonate supporting disintegration and providing a local $\mathrm{pH}$ supporting dissolution, enhances the rate of tablet disintegration and subsequent dissolution of active drug within the stomach, where it can be quickly absorbed into systemic circulation. The Biopharmaceutics Classification System (BCS) assigns aspirin to Class I (high solubility, high permeability) [24]. The quick disintegration and fast bioavailability of the new formulation supports the BCS properties of aspirin and provides pharmaceutical advantage for early onset of action.

Second, though this behavior is beneficial to any patient seeking for quick pain relief, it becomes especially critical in the context of acute migraine, which is often accompanied by impaired gastric motility. In this situation, transit of drug to the small intestine for absorption would be delayed, and onset of relief could be compromised if the drug administered is not optimized for gastric absorption. It can therefore be concluded that the pharmaceutical characteristics and the pharmacokinetic properties of the new $1,000 \mathrm{mg}$ aspirin formulation would support its efficacy in the relief of headache caused by migraine attacks with or without aura.

Aspirin is approved for self-medication in single doses of up to 1,000 mg in many countries. The current study did not provide any signal for unexpected or unknown side effects or higher frequencies of known side effects. Doses of 1,000 mg of acetylsalicylic acid have generally been proven safe and tolerable in a variety of Phase III and IV studies including migraine studies [3-13]. The maximum plasma concentration is comparable to 2 tablets of a standard dose of $500 \mathrm{mg}$ and also comparable to marketed effervescent tablet formulations [22] which are approved for the treatment of migraine headache.

\section{Conclusions}

The 1,000 mg quickly disintegrating aspirin tablet demonstrated bioequivalence compared to two tablets of commercially available 500 mg quickly disintegrating Aspirin ${ }^{\oplus}$, when administered as a single dose to healthy, fasted adults. Both formulations were safe and well-tolerated under these conditions. The $1,000 \mathrm{mg}$ aspirin formulation is appropriate for the treatment of migraine headache and provides requirements for fast onset of action.

\section{Acknowledgement}

The study was funded by Bayer AG, Leverkusen, Germany. Bayer is the originator and a major manufacturer of aspirin products. M.V. and S.F. are both employees of Bayer. The study was conducted by Frontage Clinical Services, Hackensack, New Jersey, United States.

\section{References}

1. Vos T, Abajobir AA, Abbafati C, Abbas KM, Abate KH et al (2017) Global, regional, and national incidence, prevalence, and years lived with disability for 328 disease and injuries for 195 countries, 1990-2016: a systematic analysis for the global burden of disease study 2016. Lancet 390: 1211-59.

2. Lipton RB, Baggish JS, Stewart WF, Codispoti JR, Fu M (2000) Efficacy and safety of acetaminophen in the treatment of migraine: results of a randomized, double-blind, placebo-controlled, population-based study. Arch Intern Med 160: 3486-92.

3. Boureau F, Joubert JM, Lasserre V, Prum B, Delecoeuillereie G (1994) Double-blind comparison of acetaminophen 400mg-codeine 25mg combination versus aspirin 1000mg and placebo in acute migraine attack. Cephalgia 14: 156-61.

4. Lange R, Schwarz JA, Hohn M (2000) Acetylsalicylic acid effervescent 1000 mg (Aspirin) in acute migraine attacks; a multicentre, randomized, double-blind, single-dose, placebo-controlled parallel group study. Cephalagia 20: 663-7.

5. Diener HC, Bussone G, De Liano H, Eikermann R, Englert R, et al. (2004) Placebo-controlled comparison of effervescent acetylsalicylic acid, sumatriptan and ibuprofen in the treatment of migraine attacks. Cephalalgia 24: 947-54.

6. Diener HC, Eikermann A, Gessner U, Göbel H, Haag G, et al. (2004) Efficacy of 1,000 mg Effervescent Acetylsalicylic Acid and Sumatriptan in Treating Associated Migraine Symptoms. Eur Neurol 52: 50-6.

7. Lipton RB, Goldstein J, Baggish JS, Yataco AR, Sorrentinp JV, et al. (2005) Aspirin is efficacious for the treatment of acute migraine. Headache 45: 283-92.

8. Diener HC, Lampl C, Reimnitz P, Voelker M (2006) Aspirin in the treatment of acute migraine attacks. Expert Rev Neurotherapeutics 6: 563-73.

9. Lampl C, Voelker M, Diener HC (2007) Efficacy and safety of 1,000mg effervescent aspirin: individual patient data meta-analysis of three trials in migraine headache and migraine accompanying symptoms. J Neurol 254: 705-12.

10. Tfelt-Hansen P (2008) Triptans vs Other Drugs for Acute Migraine. Are There Differences in Efficacy? A Comment. Headache 48: 601-5.

11. Lampl C, Voelker M, Steiner TJ (2013) Aspirin is First-Line Treatment for Migraine and Episodic Tension-Type Headache Regardless of Headache Intensity. Headache 52: 48-56.

12. Kirthi V, Derry S, Moore RA, McQuay H (2013) Aspirin for acute migraine headaches in adults. J Neurol Neurosurg Psychiatry 84: 585-6.

13. Kirthi V, Derry S, Moore RA, McQuay HJ (2010) Aspirin with or without an antiemetic for acute migraine headaches in adults. Cochrane Database Syst Rev 14: CD008041.

14. Cady RK, Lipton RB, Hall C, Stewart WF, O'Quinn S, et al. (2000) Treatment of mild headache in disabled migraine sufferers: results of the spectrum study. Headache 40: 792-7.

15. Cady RK, Sheftell F, Lipton RB, O'Quinn S, Jones M, et al. (2000) Effect of early intervention with sumatriptan on migraine pain: retrospective analyses of data from three clinical trials. Clin Ther 22: 1035-48.

16. Pascual J, Cabarrocas X (2002) Within-patient early versus delayed treatment of migraine attacks with almotriptan: the sooner the better. Headache 42: 28-31. 17. Mathew N, Kailasam J, Meadors L (2004) Early treatment of migraine with rizatriptan: a placebo-controlled study. Headache 44: 669-73. 
18. Goadsby PJ, Lipton RB, Ferrari MD (2002) Migraine-Current understanding and treatment. N Engl J Med 346: 257-70.

19. Voelker M, Hammer M (2012) Dissolution and pharmacokinetics of a novel micronized aspirin formulation. Inflammopharmacology 20: $225-31$.

20. Cooper SA, Voelker M (2012) Evaluation of onset of pain relief from micronized aspirin in dental pain model. Inflammopharmacology $20: 233-42$.

21. Voelker M, Schachtel BP, Cooper SA, Gatoulis SC (2016) Efficacy of disintegrating aspirin in two different models for acute mild-to-moderate pain: sore throat pain and dental pain. Inflammopharmacology 24: 43-51.

22. Kanani K, Gatoulis SC, Voelker M (2015) Influence of differing analgesic formulations of aspirin on pharmacokinetic parameters. Pharmaceutics 7: 188-98.

23. Schroer K (2016) Acetylsalicylic acid. Wiley-VCH.

24. Dressman JB, Nair A, Abrahamsson B, Barends DM, Groot DW, et al. (2012) Biowaiver monograph for immediate-release solid oral dosage forms: acetylsalicylic acid. J Pharm Sci 101: 2653-67. 